\title{
Author Correction: Targeting oxidative stress in disease: promise and limitations of antioxidant therapy
}

Henry Jay Forman (D) and Hongqiao Zhang

Correction to: Nature Reviews Drug Discovery https://doi.org/10.1038/s41573-021-00233-1, published online 30 June 2021.

In Box 1, reaction 2 has been corrected to $\mathrm{NADPH}+2 \mathrm{O}_{2} \rightarrow \mathrm{NADP}^{+}+\mathrm{H}^{+}+2 \mathrm{O}_{2}{ }^{--}$. This has been corrected in the HTML and PDF versions of the article. https://doi.org/10.1038/s41573-021-00267-5 I Published online 13 July 2021

๑) Springer Nature Limited 2021 